\title{
Promoção da saúde e higiene em berçário
}

\author{
Graciane Regina Pereira \\ Instituto Federal Santa Catarina (IFSC) \\ (gracianerp@ifsc.edu.br) \\ Rosana Regina Batista Poli \\ (rosana.poli@hotmail.com) \\ Marcelo Alberto Elias \\ Instituto Federal do Paraná (IFPR) \\ (marcelo.elias@ifpr.edu.pr)
}

Resumo: A Educação Infantil passa a ter respaldo legal e pedagógico a partir da Lei de Diretrizes e Bases da Educação. Os espaços para essa fase etária, como os Centros de Desenvolvimento Infantil - CDIs, devem superar a dicotomia entre o cuidar e o educar, com propostas pedagógicas que busquem a formação integral da criança. Esse estudo, realizado em um Centro de Desenvolvimento Infantil de Gaspar (SC), buscou promover a conscientização das educadoras do berçário (crianças de 0 a 1 ano) sobre higiene e saúde. A pesquisa, um estudo de caso, se configurou como qualitativa, exploratória, realizada por meio de aplicação de questionários e observações. A maior parte dos respondentes avaliou como bom os aspectos de higiene no ambiente de trabalho. A formação inicial para trabalhar especificamente com bebês e a formação continuada para os cuidados com higiene e saúde não ocorreu com todos os envolvidos. Realizou-se uma roda de conversa, com participação de uma enfermeira e de uma médica, registrando os pontos mais significativos para o grupo e, posteriormente, elaborou-se uma proposta de cartilha informativa. Percebeu-se que a realização do projeto sensibilizou os educadores e equipe gestora para a importância da temática saúde e higiene em berçário. As ações em um CDI vão além do cuidar, o aspecto educativo deve ser priorizado, por meio de propostas pedagógicas sistematizadas e profissionais preparados.

Palavras-chave: Higiene; Berçário; Promoção da saúde; Educação infantil.

\section{Promotion of health and hygiene in nursery}

Abstract: Early Childhood Education now has legal and pedagogical support from the "Lei de Diretrizes e Bases da Educação" (Law of Guidelines and Bases of Education). The school environment for this age phase, such as the Child Development Centers (ICDs) must overcome the dichotomy between care and education with pedagogical proposals that seek the integral formation of the child. This study, conducted at a Child Development Center located at Gaspar (SC), aimed to promote the awareness of nursery children (aged 0 to 1 year-old) educators about hygiene and health. This qualitative, exploratory research, a case study, was based on the application of questionnaires and on observations. Most respondents rate hygiene in their workplace as satisfactory. Initial training to work specifically with babies and continuous training for hygiene and health care was not attended by everyone involved. A conversation session was held with the participation of a nurse and a doctor and the most significant points for the group were registered and later a proposal for an information booklet was elaborated. It was noticed that the realization of the project has drawn educators and the management team attention to the importance of health and hygiene in nursery. The actions in an ICD go beyond caring; the educational aspect must be prioritized through systematized pedagogical proposals and prepared professionals.

Keywords: Hygiene; Nursery; Health promotion; Child education. 


\section{INTRODUÇÃO}

A função social da Educação Infantil compreende duas ações indissociáveis: cuidar e educar. A Lei de Diretrizes e Bases da Educação Nacional, aprovada em 1996 (Lei o 9.394/96), regulamenta a educação infantil como primeira etapa da educação básica, sendo sua finalidade o desenvolvimento integral da criança em seus aspectos cognitivo, afetivo, físico e social, complementando a ação da família (GASPAR, 2010).

Assim, para atender às mães que cada vez mais se inserem no mercado de trabalho e às exigências legais, surge a demanda de atendimento de crianças por instituições especializadas. Essas instituições, como espaço de convívio social e coletivo, precisam de um funcionamento adequado, proporcionando um ambiente seguro e saudável (BARBOSA; AFONSO, 2011). São as conhecidas creches.

Apesar dos cuidados, crianças em centros de desenvolvimento infantil (CDIs) têm riscos de adquirir infecções, associadas às características ambientais e à maior suscetibilidade devido aos hábitos que facilitam a disseminação de doenças, como levar as mãos e objetos à boca, contato interpessoal muito próximo e imaturidade do sistema imunológico (WEISS, 1999).

Várias atitudes e procedimentos são necessários para que 0 atendimento de bebês, no caso de 0 a 1 ano, seja mais seguro e saudável. Uma sala de berçário limpa e higienizada é necessária para o acolhimento dessas crianças. A entrada e saída de várias pessoas neste espaço sem o cuidado com o calçado, trazendo sujeiras para onde as crianças se arrastam e colocam os brinquedos que estão no chão à boca, por exemplo, foi uma das situações que motivaram a pesquisa.

O objetivo do trabalho foi entender o contexto e promover a conscientização sobre a saúde e higiene em ambiente de berçário, auxiliando na formação continuada de servidores em um Centro de Desenvolvimento Infantil de Gaspar (SC). Para realização da pesquisa utilizou como instrumentos: revisão bibliográfica, aplicação de questionários, roda de conversa e elaboração de uma cartilha.

Quanto ao caráter, tratou-se de pesquisa exploratória, com revisão bibliográfica para embasar a elaboração do questionário e a análise e discussão dos resultados. De acordo com Gil (2010, p. 43), "as pesquisas exploratórias têm como principal finalidade desenvolver, esclarecer e modificar conceitos e ideias, tendo em vista a formulação de problemas mais precisos". 
Quanto ao método, foi desenvolvida uma pesquisa bibliográfica, fundamentando-se em material já publicado, como livros, revistas, artigos e teses (GIL, 2010). O autor cita como vantagem o fato de permitir acesso aos mais diversos assuntos e fenômenos para o desempenho da pesquisa, muito mais amplo do que aquela que poderia pesquisar diretamente.

O procedimento adotado para a coleta de dados foi o estudo de caso, que se refere ao tipo de pesquisa focado em casos reais, obtendo os dados através de procedimentos de pesquisa de campo, mediante análise rigorosa e apresentado por meio de relatórios ou gráficos (SEVERINO, 2007).

Em relação ao delineamento, a pesquisa teve caráter qualitativo. Os dados foram analisados de forma descritiva tendo como base a visão contextual do problema a ser compreendido.

\section{EDUCAÇÃO INFANTIL}

No Brasil, a faixa etária de 0 a 6 anos de idade, intenso período de formação humana, foi durante longo tempo considerada de modo superficial quanto ao reconhecimento e importância dos direitos das crianças na Educação Infantil. O direito à educabilidade foi um dos centrais, tanto na Constituição Federal de 1988, quanto na Lei de Diretrizes e Bases da Educação Nacional (LDB) de 1996 (AMORIN; YAZLLE; FERREIRA, 2000).

Portanto, a Educação Infantil passa a ter seu respaldo legal e pedagógico que fundamentam sua importância. A LDB trata especificamente da Educação Infantil:

Art. 29. A educação infantil, primeira etapa da educação básica, tem como finalidade o desenvolvimento integral da criança até seis anos de idade, em seus aspectos físico, psicológico, intelectual e social, complementando a ação da família e da comunidade.

Art. 30. A educação infantil será oferecida em: I - creches ou entidades equivalentes, para crianças de até três anos de idade; II pré-escolas, para as crianças de quatro a seis anos de idade I. (BRASIL, 1996, p. 01)

No contexto da Educação Infantil, as ações de cuidar e educar foram compreendidas por longo período da história como ações estanques. O cuidar, caracterizado por ações que envolviam higiene, alimentação e sono; o educar, 
envolto às propostas pedagógicas ditas atividades dirigidas. Esta relação ou ações ficaram melhores compreendidas a partir das Diretrizes Curriculares Nacionais para a Educação Infantil (BRASIL, 2009).

Por conta do contexto coletivo vivido no interior das instituições de educação infantil, as interferências do adulto concernentes à saúde e bem-estar e ao convívio com o meio devem ser consideradas. Especificamente das crianças de 0 a 3 anos, cujo sistema imunológico apresenta fragilidades em decorrência da pouca idade. No cotidiano das instituições, deve ser considerada e compreendida a saúde como a expressividade da vida, atrelado ao ser como um todo, inserido social e historicamente (WEISS, 1999).

No contexto familiar e na creche, os cuidados com as crianças perpassam pelo significado que os sujeitos envolvidos dão a este, interferem e consequentemente retratam seu olhar para saúde e higiene nas práticas realizadas (WEISS, 1999).

Deste modo, as ações de cuidar representam aspectos sociais para promover a saúde e também a educação das crianças. Portanto, não se podem desconsiderar os cuidados com a saúde enquanto se realiza uma proposta pedagógica, ou seja, há que se ter acesso ao conhecimento das áreas de saúde e pedagógicas para que na prática se consolide a função social da educação das crianças (MARANHÃO, 2010).

Nas instituições de educação Infantil, há que se ter conhecimento prévio de alguns cuidados básicos quanto à higiene local e pessoal. Neste caso, há que se ter na gestão e nas políticas públicas um comprometimento para garantir ao adulto responsável as possibilidades de formação contínua, bem como as parcerias com a secretaria de saúde do município (WEISS, 1999).

\subsection{0 papel do docente em sala de berçário}

A Proposta Pedagógica para o atendimento da criança em creche (BRASIL, 1993) discorre sobre a identidade dos profissionais da educação infantil, utilizando o termo monitoras, e que essas deveriam passar grande parte de seu tempo e do tempo das crianças realizando atividades manuais, definindo que toda função exercida nas creches deva ter um caráter educativo, pois todas as pessoas que trabalham, direta ou indiretamente, com a criança, são educadores, independentemente de suas funções (MARAFON, 2013). 
Nas creches ainda é significativo o número de profissionais sem formação escolar mínima. A Lei nº 9.394/96 dispõe no título IX, art. 87, § 4ํque: até o fim da década da Educação somente serão admitidos professores habilitados em nível superior ou formados por treinamento em serviço (BRASIL, 1996). Isto significa que as diferentes redes de ensino deverão investir de maneira sistemática na capacitação e atualização permanente e em serviço de seus professores (sejam das creches ou pré-escolas), aproveitando as experiências acumuladas daqueles que já vêm trabalhando com crianças há mais tempo e com qualidade.

Liberato, Pottmaier e Jenichen (2017) apontam que as atividades do docente no berçário abrangem alimentação, troca de fraldas, atividades e repouso. Destaca ainda Oliveira (2010) apud Liberato, Pottmaier e Jenichen (2017, p. 05):

O cotidiano dessas unidades, enquanto contextos de vivência, aprendizagem e desenvolvimento, requer a organização de diversos aspectos: os tempos de realização das atividades (ocasião, frequência, duração), os espaços em que essas atividades transcorrem (o que inclui a estruturação dos espaços internos, externos, de modo a favorecer as interações infantis na exploração que fazem do mundo), os materiais disponíveis e, em especial, as maneiras do professor exercer seu papel (organizando o ambiente, ouvindo as crianças, respondendo-lhes de determinada maneira, oferecendo-Ihes materiais, sugestões, apoio emocional, ou promovendo condições para a ocorrência de valiosas interações e brincadeiras criadas pelas crianças, etc.).

O Referencial Curricular Nacional para a Educação Infantil (BRASIL, 1998) destaca, ainda, que o trabalho direto do docente com crianças pequenas exige que o professor tenha uma competência polivalente, devendo trabalhar com conteúdo de natureza diversos que abrangem desde cuidados básicos essenciais até conhecimentos específicos provenientes das diversas áreas do conhecimento.

$\mathrm{Na}$ formação docente, a prática de medidas higiênicas tem como metas básicas instituir hábitos de cuidado com o corpo, garantir o estado de higidez e prevenir doenças.

Alves e Veríssimo (2007) identificaram em seu estudo que as professoras não usam conhecimento formal ao oferecer cuidados às crianças, e que se sentem inseguras ao lidar com as doentes. Apontam que há uma lacuna na formação dos profissionais em relação a essa competência.

A Prefeitura Municipal de São Paulo (2008) disponibilizou um Manual de Boas Práticas de Higiene e de Cuidados com a Saúde para Centros de Educação Infantil 
(CEI), orientando os professores a adotarem medidas de prevenção simples que visam diminuir a transmissão de doenças. Ressalta ainda que a implantação desses cuidados de saúde e higiene pessoal tem influência direta na garantia das condições adequadas de saúde coletiva e individual nos CEls. A implantação dessas medidas faz com que o risco de transmitir ou adquirir doenças torne-se muito baixo.

[...] as práticas de cuidado necessárias à manutenção e recuperação da saúde infantil só podem ser implementadas pelos cuidadores à medida que estes tenham sido capacitados para isso, o que torna evidente a necessidade de que a formação das educadoras de creches contemple esse componente do cuidado. (ALVES; VERÍSSIMO, 2007, p. 15)

Referencia Fontana (2008) que os Parâmetros Curriculares Nacionais constituem uma proposta educacional que busca orientar o desenvolvimento do trabalho educacional e estabelecer um currículo que seja capaz de atender às necessidades do aluno. Existem inúmeros conhecimentos que podem ser trabalhados voltados à vigilância em saúde, sugerindo as condições do ambiente, as relações de alimentação, as condições essenciais à manutenção da saúde, medidas de prevenção das doenças, entre outras.

Conforme as Diretrizes Curriculares Nacionais para a Educação Infantil (BRASIL, 1998) e Vieira (2016), o cuidar faz parte da educação, devendo as necessidades das crianças serem observadas, ouvidas e respeitadas. A promoção da saúde está inclusa nessas necessidades atendidas pelo ato de cuidar, a partir de conhecimentos específicos sobre o desenvolvimento biológico, emocional e intelectual das crianças. Para que haja o desenvolvimento de ações de forma integrada, o professor precisa se comprometer com todas as crianças, estabelecendo um vínculo com elas para que consiga identificar suas necessidades e passe a priorizá-las, a ponto de atendê-las de forma adequada.

\section{METODOLOGIA}

O estudo foi realizado no ambiente de berçário, em um Centro de Desenvolvimento Infantil (CDI), localizado no município de Gaspar, em Santa Catarina. 
A população desse estudo foi formada pelos colaboradores do Centro de Desenvolvimento Infantil. A amostra foi caracterizada pelos colaboradores que atuam nesta sala: duas professoras, duas auxiliares de professora, membros da equipe gestora (direção, coordenação e secretária) e os responsáveis pela limpeza (serventes).

As técnicas de coleta de dados foram: aplicação de questionário; realização de roda de conversa com a equipe escolar para ampliar os conhecimentos de promoção da saúde das crianças ou bebês; e elaboração de uma cartilha informativa, conforme descrito a seguir:

1. Elaboração do questionário: o questionário, com perguntas abertas, buscou levantar questões práticas do dia a dia do berçário, a fim de identificar as ações de higiene, o conhecimento dos profissionais e a promoção da saúde no ambiente. O questionário elaborado possuiu dez.

2. Aplicação do questionário: os profissionais que formaram a amostra foram convidados a participar do estudo na sala dos professores do local de estudo. A partir das explicações, decidiram, por livre e espontânea vontade, pela aceitação, ou não, em participar da pesquisa assinando o Termo de Consentimento Livre e Esclarecido. A aplicação ocorreu no CDI, após a jornada de trabalho.

3. Análise dos resultados do questionário: após a aplicação do questionário à amostra de colaboradores, os resultados foram analisados e interpretados. A análise teve como objetivo organizar e sumariar os dados para possibilitar o fornecimento de respostas ao problema proposto para a investigação. Já a interpretação teve como objetivo a procura do sentido mais amplo das respostas, o que é feito mediante sua ligação a outros conhecimentos anteriores obtidos (GIL, 2010). Os resultados foram apresentados em quadros e figuras, além de textos explicativos. A identidade dos sujeitos participantes da pesquisa foi preservada, mantendo-os no anonimato.

4. Roda de conversa: foi realizada entre a amostra do estudo, uma médica e uma enfermeira do posto de saúde do bairro onde está localizado o Centro de Desenvolvimento Infantil. A médica explanou sobre cada dúvida oriunda da etapa anterior. As falas foram gravadas para posteriormente serem transcritas e analisadas. Utilizou-se a análise qualitativa através de análise de discursos. A roda de conversa ocorreu uma semana após o recolhimento dos 
questionários respondidos, no período noturno, com duração de uma hora e trinta minutos.

5. Elaboração de uma proposta de ação para o Centro de Desenvolvimento Infantil: após a revisão bibliográfica e análise dos resultados da pesquisa, foi construída uma cartilha educativa que ficará no Centro de Desenvolvimento Infantil como instrumento de orientação para os funcionários.

\section{RESULTADOS E DISCUSSÃO}

\subsection{Perfil dos respondentes}

Com relação ao grau de instrução dos respondentes: 1 pessoa tem pósgraduação, 3 pessoas superior; 2 superior incompleto; 1 ensino médio completo; 1 ensino médio incompleto e 1 ensino fundamental completo. Os respondentes que possuem o superior completo estão concentrados nos cargos da área pedagógica e administrativa. Todos os respondentes são do sexo feminino.

Com relação à participação dos respondentes em formação inicial para o trabalho específico com bebês, 6 disseram não receber e 3 afirmaram que receberam formação inicial.

Considerando a formação continuada, 5 participantes afirmaram que não há formação continuada voltada para os cuidados necessários de higiene e saúde, e 4 apontaram que receberam formação continuada voltada para os cuidados necessários de higiene e saúde.

\subsection{Percepção sobre as condições de higiene e saúde}

A segunda parte do questionário, com questões abertas, levantou a percepção dos funcionários sobre as ações de higiene e a promoção da saúde no ambiente. Os resultados apontam que 6 participantes consideram bom os aspectos de higiene no ambiente de trabalho; 2 consideram regular e 1 considera insatisfatório. 
Com relação ao conhecimento dos respondentes sobre as diretrizes e/ou legislação que estabelecem critérios ou normas para as condições do ambiente e ações laborais relacionadas à higiene, 6 entrevistados conhecem, 2 conhecem parcialmente e 1 não conhece.

$\mathrm{Na}$ figura 1 é apresentada a percepção dos respondentes sobre quais materiais e/ou equipamentos consideram necessários para realizar as ações de cuidado/higiene na sala do berçário.

Figura 1: Materiais e/ou equipamentos necessários para cuidado/higiene segundo respondentes.

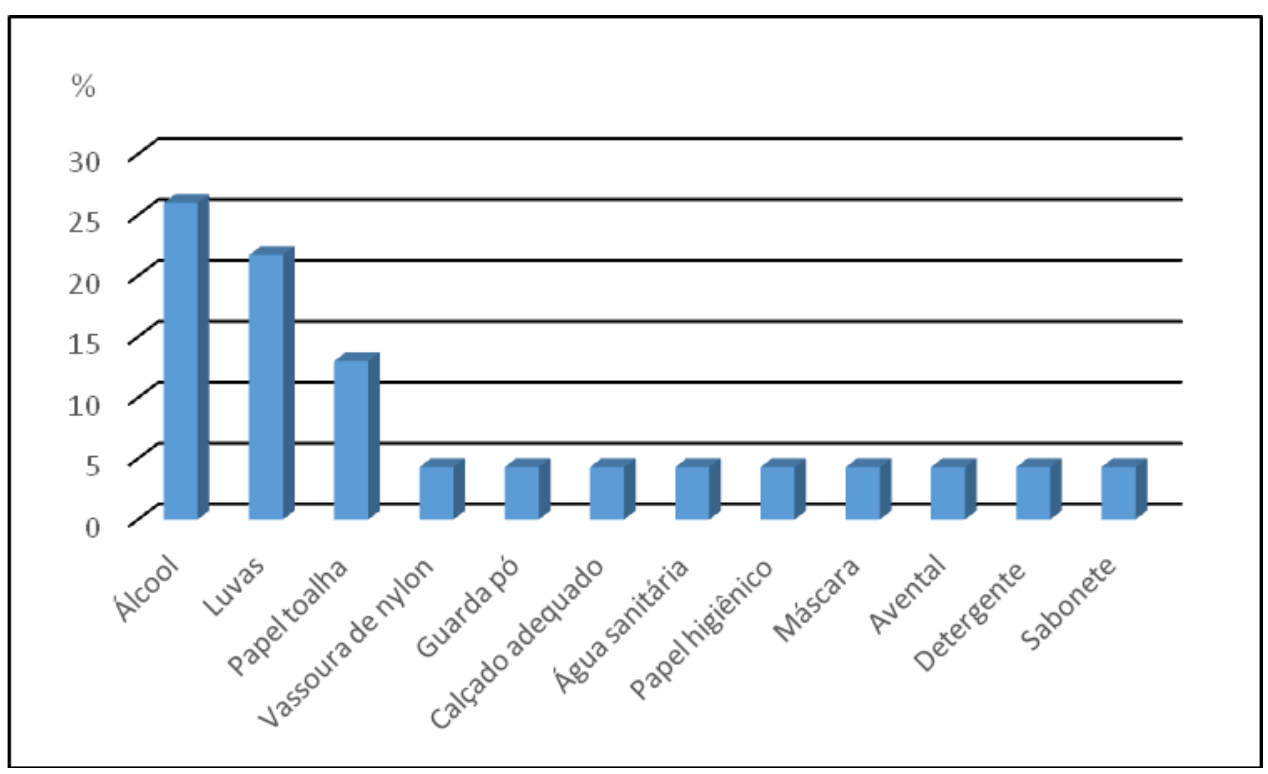

Fonte: Autores

Conforme a figura 1, o álcool foi citado por 6 respondentes; 5 respondentes citaram as luvas; 3 funcionários o papel-toalha e 2 funcionários a vassoura de nylon. Os seguintes materiais e/ou equipamentos: lenço umedecido, guarda pó, calçado adequado, água sanitária, papel higiênico, máscara, avental, detergente e sabonete foram citados uma vez.

A questão seguinte, visualizada na figura 2, mostra a porcentagem da percepção dos respondentes sobre as doenças mais comuns de serem contraídas pelos bebês na sala do berçário. 
Figura 2: Doenças comuns no berçário, segundo respondentes.

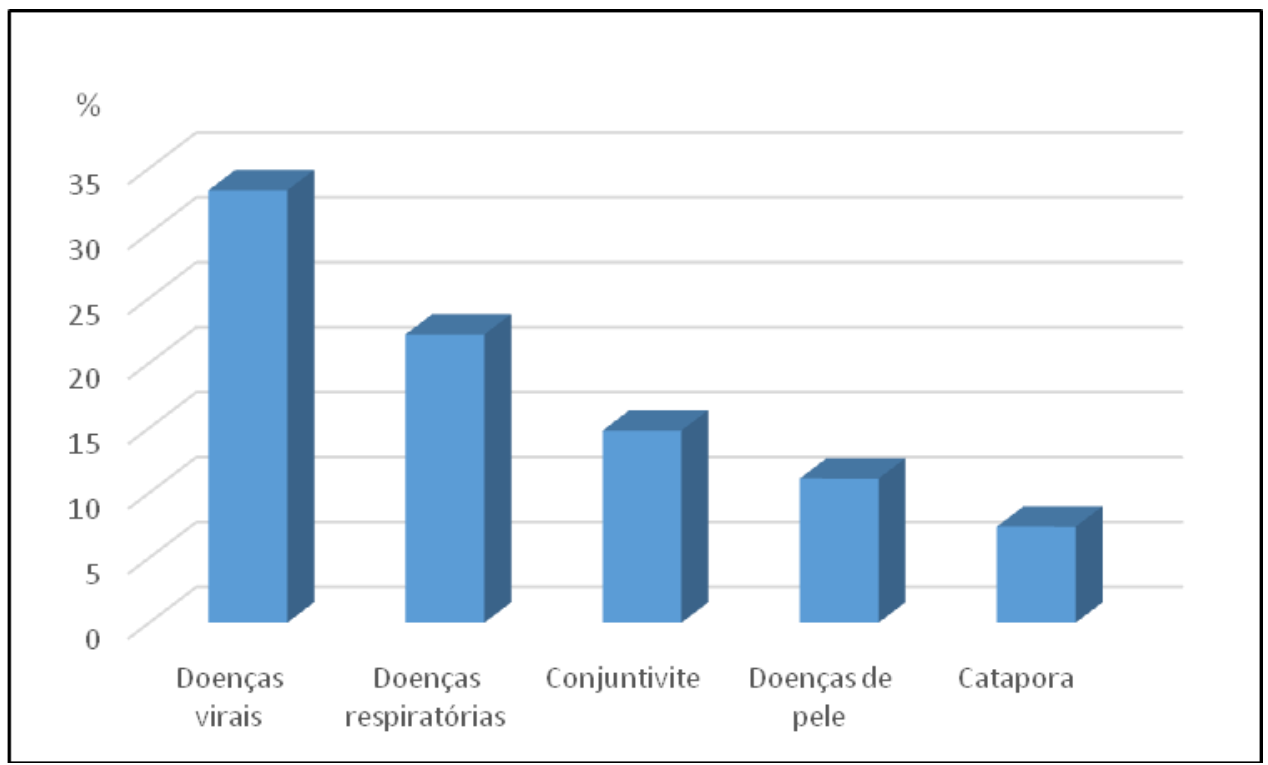

Fonte: Autores

Observa-se na figura 2 que as doenças virais diversas foram as mais citadas, seguidas das doenças respiratórias, a conjuntivite, as doenças de pele e a catapora.

O trabalho de Pedraza, Queiroz e Sales (2014) aponta o agrupamento de crianças numa situação de diária e prolongada coexistência (10-12 horas), recebendo atendimento de forma coletiva, em locais fechados e sem condições de higiene adequada pode facilitar a disseminação de doenças, conferindo à creche epidemiologia característica na transmissão de infecções, ou seja, é comum a existência de doenças, em especial as respiratórias. O trabalho também ressalta que alguns agentes de infecções respiratórias também podem ser transmitidos através da via fecal-oral, e para isso a higiene pessoal é ponto significativo na prevenção dessas doenças.

Nesti e Goldbaum (2007) ressaltam que os microrganismos responsáveis por estes quadros infecciosos de doenças respiratórias, as mais comuns, são os mesmos que acometem crianças cuidadas em casa. As crianças que frequentam creches, especialmente antes dos 3 anos de idade, têm episódios infecciosos de vias aéreas superiores mais severos e em maior número, aproximadamente o dobro, sendo que o risco aumenta com o número de horas passadas na creche. 
A diarreia consiste em outra doença de grande incidência nas creches, cuja transmissão se dá pelo contato direto, geralmente pelas mãos, ou objetos e superfícies da creche. A troca de fraldas é considerada o procedimento de maior risco para a transmissão de enteropatógenos entre crianças e funcionários de creches, por isso medidas preventivas de higiene são tão importantes (NESTI E GOLDBAUM, 2007).

Na questão sobre atitudes de cada participante para a promoção da saúde no berçário, os respondentes citaram as seguintes ações: higienização da sala de berçário, lavagem das mãos, retirada do calçado antes de entrar, reposição dos produtos de higiene, verificação do ambiente, utilização do álcool e papel higiênico para não passar microrganismos para outras crianças.

O trabalho de Nesti e Goldbaum (2007) recomenda cuidados similares e contínuos nas creches como forma de prevenção das doenças: lavagem apropriada das mãos após exposição; utilização de precauções padrão; rotina padronizada para troca e descarte de fraldas usadas, localização e limpeza da área de troca, limpeza e desinfecção de áreas contaminadas; uso de lenços descartáveis para assoar o nariz; funcionários e área exclusivos para a manipulação de alimentos; notificação das doenças infecciosas; treinamento de funcionários e orientação dos pais.

Por fim, a última questão buscou identificar as dúvidas em relação aos cuidados mínimos necessários para manter um ambiente saudável em sala de berçário, quais foram:

- Conhecimento da imunidade dos bebês;

- utilização de luvas no berçário;

- importância de os pais trazerem babador, toalha e pano para higienização individual dos bebês;

- higienização dos brinquedos;

- higienização dos trocadores;

- ventilação da sala do berçário.

\subsection{Roda de conversa}

A partir das respostas e dúvidas identificadas no questionário, foi realizada a roda de conversa com os envolvidos na pesquisa. Uma médica e uma enfermeira do posto de saúde do bairro onde está localizado o CDI foram as responsáveis por 
atender os questionamentos listados na etapa anterior e conduzir a conversa. As principais orientações dadas pelas profissionais foram registradas:

- utilização de álcool líquido a 70\% para higienização do ambiente e utensílios;

- para a higienização das mãos, deve-se lavar as mãos e depois utilizar álcool líquido ou álcool gel a 70\%. Acima de 70\%, o álcool perde a função de matar as bactérias;

- uso de álcool gel não substitui a lavação das mãos;

- limpeza do trocador e superfície de modo geral: limpeza com água e detergente e, por fim, utilizar álcool líquido. Entre uma troca e outra, poderá ser utilizado somente o álcool;

- chão do berçário: utilização de calçado apenas para dentro da sala, como chinelos;

- não há necessidade da utilização de luvas para trocar as fraldas de xixi. Essa proteção é feita apenas para proteger quem está limpando. A lavação das mãos já é suficiente;

- uma boa higienização das mãos substitui as luvas;

- imunidade dos bebês: os bebês nascem com a imunidade que a mãe passou durante a gestação. Após o nascimento, essa imunidade aumenta conforme as vacinas recebidas e o aleitamento materno. A imunidade começa a ser produzida a partir dos 3 anos. Diz-se que a imunidade está baixa quando o corpo recebe as doenças e não consegue combater;

- normalmente, uma criança que frequenta a creche terá uma média de 12 a 14 infecções ao ano;

- as principais doenças que acometem os bebês são virais;

- as formas de contágio mais comuns são: contato de pele, gotículas de saliva e pelo ar;

- importância de realizar a lavagem nasal nas crianças com soro fisiológico para retirar o muco nasal e prevenir que uma infecção leve vire uma infecção bacteriana;

- quando a criança está doente, pode-se solicitar aos pais ou responsáveis o comprovante de comparecimento no posto de saúde ou a receita médica;

- ar condicionado não faz mal para os bebês, desde que tenha sido feita a manutenção do equipamento. Mas, a sala deve ser arejada algumas vezes ao dia; 
- toalha de pano coletiva: doença por contato será transmitida se a mão não tiver sido bem lavada;

- ventilação da sala do berçário de 2 a 3 horas, de manhã e à tarde, criando um circuito para o ar ser trocado;

- casos de diarreia não tem tratamento, esperar passar, hidratando a criança;

- professora gripada, desde que esteja bem, pode trabalhar;

- limpeza dos brinquedos de plástico pode ser feita com álcool líquido. Ideal seria não ter brinquedos de pelúcia.

A roda de conversa se mostrou enriquecedora aos participantes, que aprenderam a realizar de maneira correta a higiene e limpeza do local, além de aspectos de promoção à saúde.

\subsection{Cartilha}

O terceiro objetivo definido foi colaborar com a promoção à saúde no berçário, sendo elaborada uma cartilha informativa que para o CDI como instrumento de orientação para os funcionários.

A cartilha abordou os seguintes temas: a saúde e higiene pessoal dos funcionários; a saúde e higiene das crianças; e os cuidados no consumo dos alimentos. O texto foi construído a partir dos estudos bibliográficos e dos resultados da pesquisa. A cartilha, com 12 páginas, apresentou uma linguagem clara e foi direcionada aos funcionários que atuam em berçário.

\section{CONCLUSÃO}

O trabalho levantou informações sobre o contexto do ambiente de berçário em um Centro de Desenvolvimento Infantil de Gaspar (SC) e promoveu a conscientização sobre a saúde e higiene, auxiliando na formação continuada dos servidores.

Após a análise dos resultados coletados com a aplicação do questionário, observou-se que a maior parte dos respondentes avalia como bom os aspectos de 
higiene no seu ambiente de trabalho, além de terem conhecimento sobre as diretrizes e/ou legislação que estabelece critérios ou normas para as condições do ambiente e ações laborais relacionadas à higiene.

A maior parte dos entrevistados não recebeu formação inicial para trabalhar especificamente com bebês, para a maior parte da amostra não há formação continuada voltada para os cuidados necessários de higiene e saúde. Isso também foi apontado no trabalho de Nesti e Goldbaum (2007), há pouco treinamento nos diferentes aspectos da assistência à criança relacionados à saúde, incluindo as práticas de manuseio de alimentos.

Em sala de berçário, por ser ambiente de convívio coletivo, as doenças mais comuns de serem contraídas pelos bebês e citadas pelos respondentes foram: doenças virais, doenças respiratórias, conjuntivite, catapora e doenças de pele. Em relação à promoção da saúde no berçário, os respondentes apontaram como contribuições principais realizadas: higienização da sala, lavação das mãos e a retirada do calçado antes de entrar na sala do berçário.

A realização de roda de conversa com profissionais da saúde que atuam no bairro foi significativa e esclareceu vários questionamentos, de forma profissional. Essas informações auxiliaram no desenvolvimento da cartilha educativa, que ficará no Centro de Desenvolvimento Infantil como instrumento de orientação para os funcionários, destacando a saúde e higiene pessoal dos funcionários e das crianças e a higiene e cuidados no consumo dos alimentos.

Por fim, recomenda-se a realização de trabalhos futuros sobre o tema abordado, pois esse assunto não se esgota com a finalização desse estudo, bem como a realização de oficinas com toda a equipe escolar que permita a ampliação de conhecimento para melhorias na promoção da saúde das crianças ou bebês, com imagens educativas e exemplos práticos voltados à promoção da saúde.

Além de uma formação mais robusta, é essencial uma articulação da instituição educativa com as unidades de saúde da região. Estas parcerias auxiliam e reforçam o trabalho desenvolvido pelos educadores, objetivando ampliar ainda mais o acesso da comunidade aos bens de saúde e educação.

\section{Referências}


ALVES, R. C. P.; VERÍSSIMO, M. de la O. R. Os educadores de creche e o conflito entre cuidar e educar. Rev Bras Crescimento Desenvolv Hum., v. 17, n. 1, p. 13-25, 2007.

AMORIN, K. S.; YAZLLE, C.; FERREIRA, M, C. R. Binômios Saúde-Doença e Cuidado-Educação em Ambientes Coletivos de Educação da Criança Pequena. Rev. Bras. Cresc. Desenv. Hum., São Paulo, v. 10, n. 2, p. 13-25, 2000. Disponível em: <https://www.revistas.usp.br/jhgd/article/view/39621/>. Acesso em: 27 jul. 2017.

BARBOSA, R. C.; AFONSO, M. A. V. Educação Infantil: Das Práticas Pedagógicas às Políticas Públicas. João Pessoa: UFPB, 2011.

BRASIL. Ministério do Bem-Estar Social. Proposta Pedagógica para o Atendimento da criança em Creche. Brasília, 1993.

. Lei no 9.394, de 20 de dezembro de 1996. Estabelece as diretrizes e bases da educação nacional. Disponível em:

<http://www.planalto.gov.br/ccivil_03/Leis/19394.htm>. Acesso em: 10 set. 2017.

. Ministério da Educação e do Desporto. Secretaria de Educação

Fundamental. Referencial Curricular Nacional Para a Educação Infantil.

Brasília: MEC/SEF, 1998.

. Ministério da Educação. Secretaria de Educação Básica. Diretrizes

Curriculares Nacionais para Educação Infantil. Parecer ํㅜ 05, aprovado em 17 de dezembro de 2009. Disponível em:

<http://ndi.ufsc.br/files/2012/02/Diretrizes-Curriculares-para-a-E-I.pdf>. Acesso em: 10 set. 2017.

FONTANA, R. T. A vigilância sanitária no contexto escolar: um relato de experiência. Rev Bras Enferm, Brasília, v. 61, n. 1, jan./fev. 2008.

GASPAR. Secretaria Municipal de Educação. Proposta pedagógica da rede municipal: educação infantil. In: DIAS, Julice; SANTOS, Patrícia Helena; DIAS, Sanira Cristina (Orgs.). Blumenau, 2010.

GIL, A. C. Como elaborar projeto de pesquisa. 5. ed. São Paulo: Atlas, 2010.

LIBERATO, A. C. V.; POTTMAIER, E.; JENICHEN, M. N. Vivenciando o ser professor de educação infantil no berçário: explorações sensoriais. REDIVI Revista de Divulgação Interdisciplinar, Seção: Núcleo das Licenciaturas, v. 5, n. 1.2, p. 1-26, 2017.

MARANHÃO, D. G. Saúde e bem estar das crianças: Uma Meta Para Educadores Infantis em Parceria com Familiares e Profissionais de Saúde, 2010.

Disponível em: <http://portal.mec.gov.br/docman/dezembro-2010-pdf/7157-25-artigo-mec-saude-bemestar-criancas-damaris/file>. Acesso em: 27 jul. 2017. 
MARAFON, D. Entre uma pedagogia da assistência e uma pedagogia compensatória: Proposta pedagógica para o atendimento da criança em creche (1993). Revista Linhas, Florianópolis, v. 14, n. 26, jan./jun. 2013.

NESTI, M. M. M.; GOLDBAUM. M. As creches e as doenças transmissíveis. Jornal de Pediatria - Vol. 83, №4, 2007. Disponível em:

<http://www.scielo.br/pdf/jped/v83n4/v83n4a04.pdf>. Acesso em: 15 mar. 2019.

PEDRAZA, D. F.; QUEIROZ, D.; SALES, M. C. Doenças infecciosas em crianças pré-escolares brasileiras assistidas em creches. Ciênc. saúde coletiva. 19 (02) Fev 2014. Disponível em:

<https://www.scielosp.org/article/csc/2014.v19n2/511-528/pt/\#>. Acesso em: 15 mar. 2019.

PREFEITURA MUNICIPAL DE SÃO PAULO. Manual de boas práticas de higiene e de cuidados com a saúde para Centros de Educação Infantil. São Paulo: Coordenação de Vigilância em Saúde, 2008.

SEVERINO, A. J. Metodologia do Trabalho Científico. 23. ed. São Paulo: Cortez, 2007.

VIEIRA, I. C. da S. As práticas de professoras de berçário no contexto da proposta pedagógica de uma creche municipal do interior de São Paulo: a interação e a brincadeira em destaque. 2016. 140 f. Dissertação (Mestre em Educação), Universidade Estadual Paulista Júlio de Mesquita Filho, Presidente Prudente, São Paulo, 2016.

WEISS, E. M. G. O Cuidado na Educação Infantil: contribuições da área da saúde. Perspectiva, Florianópolis, v. 17, n. especial, p. 99-108, jan./jun. 1999. Disponível em: <https://periodicos.ufsc.br/index.php/perspectiva/article/view/10550>. Acesso em: 27 jul. 2017. 